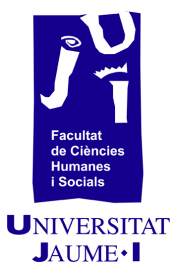

\title{
La ciudad moderna y su influencia en el escritor
}

David Martínez Robles al318837@uji.es 


\section{Resumen}

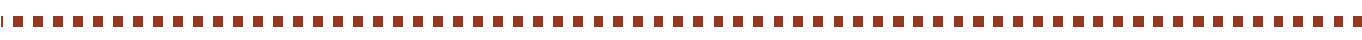

En el presente artículo se ha tenido como objetivo indagar acerca de la relevancia que ha tenido uno de los elementos mas influyentes de la historia en los escritores a la hora de realizar sus obras. Ese componente será la Ciudad moderna, es decir, la Ciudad industrial, que surge a finales del siglo XVIII y principios del siglo XIX.

Para poder comprender la gran relevancia de la ciudad, a lo largo del trabajo entraremos de lleno en las obras de tres escritores, de distintas épocas, pero que tienen en común ese enlace con la Ciudad moderna y, por tanto, la influencia de la metrópolis en estos escritos concretos. Esos tres autores son Edgar Allan Poe, Charles Baudelaire y Federico García Lorca. Así pues, veremos qué influencia ha tenido la metrópolis en la elaboración de sus escritos.

Palabras claves: ciudad moderna, metrópolis, Poe, Baudelaire, Lorca, flâneur, escritor.

\section{Introducción}

El inicio de esta investigación surge por la curiosidad que me produjo observar que el escritor, a la hora de hacer su producción literaria, tiene una gran variedad de elementos que le subjetivan, y que le dan a sus obras unas características concretas según sus vivencias. Entre esos elementos condicionantes, podemos encontrar la situación amorosa del artista, el paso de los años en el artista, la expresión de cómo se siente ante esa situación, etc.

A partir de esto, y siguiendo la idea del escritor Ernst Fischer (1972), la espontaneidad es el talento esencial del artista, su principal arma ante diferentes situaciones que muchas veces vienen de imprevisto (muerte, guerra), por lo cual, el artista se convierte en un organizador de lo espontaneo, en su obra plasma una "realidad» en la que se encuentra diferentes condiciones sociales, prejuicios, tradiciones... es decir, un mundo que está compuesto por una infinidad de elementos exteriores perceptibles que crean la realidad.

Visto, pues, que hay distintos condicionantes, vamos a ver uno muy concreto, y que tal vez haya sido uno de los elementos más influyentes en los artistas. Ese elemento es la ciudad y más en concreto la ciudad moderna surgida en el siglo XVIII.

Por tanto, este trabajo se centrará en analizar las diferentes obras de los escritores Edgar Allan Poe, Charles Baudelaire y Federico García Lorca, y en observar la evolución que se ha ido produciendo a lo largo de la historia, siguiendo la clasificación de Kristiaan Versluys, que apuntará que esta nueva relación surgida entre el escritor y la 
ciudad se puede clasificar cronológicamente en tres etapas. La primera, el Romanticismo, en la cual surge el tema de la ciudad para el escritor, aunque se le dará un enfoque negativo en pos del recuerdo de la naturaleza frente a la fría y vacía ciudad. La segunda, conocida como transición, se producirá una relación de amor y odio, es decir, una relación llena de ambigüedades. La última etapa es la Modernidad, en la cual la ciudad se ha desarrollado y se tendrá una visión sin esperanza sobre ella.

\section{Objetivos}

El objetivo principal de este trabajo ha sido averiguar si la urbe, la ciudad moderna, ha sido un elemento positivo o, por el contrario, negativo a la hora de la realización de las obras literarias de los escritores.

\section{Material y método}

En este trabajo hemos analizado obras concretas como El hombre de la multitud, Los crímenes de la calle Morgue y El misterio de Marie Rogêt, de Edgar Allan Poe. De Charles Baudelaire, veremos su obra cumbre Las flores del mal, los poemas El Sol y A una transeúnte. Y de Federico García Lorca, hemos trabajado su obra Poeta en Nueva York y los poemas Los negros y Oficina y denuncia.

\section{La ciudad}

La metrópolis, "ciudad-madre», es el útero artificial, construido para poner al hombre a cubierto frente a la intemperie de la naturaleza. En oposición al carácter penitencial del nomadismo, la vida urbana aparece, de antiguo, asociado al orgullo, causante de todos los excesos (López Castellón, 1999: 66).

A mediados del siglo XVIII, comienza a producirse la Revolución Industrial, iniciada en Gran Bretaña y luego expandida por Europa y el resto del mundo a lo largo del siglo XIX. Esta revolución producirá un gran avance tecnológico y científico que provocará un gran seísmo en la sociedad del momento. El centro del mundo será la ciudad, por lo que se producirá una migración de la población rural hacia las ciudades, la maquinaria se introducirá en la vida laboral del hombre e irá desplazando poco a poco al hombre en muchas tareas, el florecimiento de grandes empresas, el surgimiento de una nueva clase social, la clase obrera, y su organización en las fábricas, entre otros. Todas estas novedades se congregarán en lo que también es algo nuevo para el mundo, la metrópolis, la gran ciudad industrial, que se convierte en el centro neurálgico de la sociedad industrial y, 
por tanto, el centro del mundo. Con la Revolución Industrial, se inicia una nueva época en la sociedad, debido a los cambios tanto de aspecto social, económico y político; cambios, en definitiva, del estilo de vida, de manera que la ciudad se convierte en el medio primario del ser humano.

Así pues, el artista se encuentra ante una nueva situación totalmente enigmática e inhóspita, pues tiene delante un nuevo mundo, con un sinfín de nuevas experiencias y sensaciones, que aún desconoce, producidas por los nuevos elementos procedentes de la ciudad industrializada.

\section{Edgar Allan Poe}

Edgar Allan Poe, conocido como Edgar Poe -debido a que Allan le fue añadido por su familia adoptiva-, nació en Boston el 19 de enero de 1809 , en una familia en constante movimiento, porque sus padres eran actores. Quedó huérfano a la temprana edad de tres años. Fue acogido por una familia adinerada, aunque nunca fue adoptado oficialmente. Pasó un curso académico en la Universidad de Virginia y, más tarde, durante un periodo corto de tiempo, estuvo enrolado en el ejército. En el año 1935, contrajo matrimonio con su prima Virginia Clemm, hasta que ella murió de tuberculosis en el año 1847. La muerte, ya desde su nacimiento, estuvo presente a lo largo de su vida hasta que falleció en 1849.

Seguramente, El hombre de la multitud, publicado en 1841, describe perfectamente lo que era el nuevo escenario de la humanidad, la ciudad industrial y los actores que la componían.

La obra nos narra cómo un hombre, tras haber superado una enfermedad, pasa su tiempo en un café de la ciudad de Londres. Allí, observando por la ventana, capta algo que le produce una gran fascinación: la multitud de la calle. El narrador, fijándose en su vestimenta, rasgos faciales o su manera de actuar, comienza a clasificar a los transeúntes según la clase social a la que pertenezcan, incluso donde viven. El hombre que observa se encuentra feliz viendo a la gente circular y la analiza; llega a la conclusión de que, aunque esas personas se encuentran en la metrópolis $-\mathrm{y}$ esta, por tanto, está llena de gente en todos los rincones, por lo que se transmite una sensación de alboroto y vivacidad-, se encuentran en absoluta soledad.

A medida que cae la noche, el narrador observa que la multitud, que hasta en ese momento había observado, cambió; la gente del día, la que tenía rasgos amables, daba paso a la otra cara de la moneda: la muchedumbre que solo daba la cara durante la noche. El narrador, en este nuevo entorno, se percata de un anciano, que tendría unos sesenta y cinco o setenta años, de estatura baja y con aspecto débil, que a primera vista parecía que llevaba ropa típica de 
un vagabundo. Sin embargo, al observarlo mejor ve que la camisa que lleva es de una buena tela o que lleva escondido un diamante bajo su abrigo. Ante esta incoherencia, el protagonista decide salir del café y seguir al anciano que le había provocado una gran curiosidad. Este, que nunca se percata de la presencia del narrador, comienza a dirigirse por la zona más viva de Londres, pasando por tiendas y comercios, pero sin comprar nada. Entrada la noche, el anciano, que prácticamente no interrumpe su andar, acaba junto con el narrador en periferia de la ciudad, donde se encontraba lo peor de Londres.

Al cabo de un tiempo, vuelven de nuevo al centro y, después de pasar una noche entera y ya en el amanecer del día siguiente, lo vuelve a seguir hasta esa noche, en la que el protagonista, exhausto, se pone frente al anciano, mirándolo. Este, que no se percata de él, continúa con su camino. El narrador saca la conclusión de que ese hombre era el modelo del crimen, el que no puede estar en soledad, ya que siempre se encontraba en la multitud, y lo llama el hombre de la multitud.

En el siguiente cuento, Los crímenes de la calle Morgue, publicado posteriormente, cambia de escenario y nos lleva a la ciudad de París. En esta historia nos encontramos con dos detectives, uno es el narrador, aunque no se dice su nombre, y el otro es $C$. Auguste Dupin, hombre que procedía de una familia bien acomodada, pero que, por una serie de circunstancias, se encontraba en la pobreza. Se conocieron debido a repetidos encuentros $y$, gracias a eso y porque uno de los protagonistas se había quedado fascinado con el señor Dupin y que, además, buscaba un compañero para vivir en París, se fueron juntos a vivir a una mansión parisina abandonada.

Un día, los protagonistas se enteran de la noticia del asesinato de dos damas, madame l'Espanaye y su hija mademoiselle Camille. Fueron encontradas muertas en su casa totalmente mutiladas. A pesar de que hubo vecinos que escucharon los gritos de las damiselas, en ninguna de sus declaraciones se encontraba vía alguna de investigación, salvo que se escuchaban dos voces en el interior. Unido a esto, la policía no encontró pistas aparentes en el lugar del crimen, y llevó a la cárcel a un presunto sospechoso, pero sin pruebas que refutaran de ello. Dupin y su compañero deciden una investigación por su cuenta.

Dupin, un hombre muy escrupuloso, mediante una serie de observaciones de la escena del crimen, llega a la hipótesis de que el asesino fue en realidad un animal, un orangután. Para intentar demostrarlo, Dupin pone un anuncio en el periódico, en el cual se decía que se había encontrado un orangután y que para recuperarlo había que ir a la dirección de los protagonistas. Al cabo de un tiempo, se presenta allí un marinero maltés, que cuenta que se había llevado 
a la urbe al orangután -que había traído de un viaje a la India. Sin embargo, un día que volvió a su casa, el orangután se escapó y había entrado en casa de las damas y que él no había podido hacer nada por evitar tan macabro siniestro; el animal presentaba una furia descomunal y no pudo hacer nada para detenerlo, por lo cual decidió irse y dejó la situación tal como la encontró posteriormente la policía. Gracias a las concluyentes declaraciones del pirata se produjo la resolución del asesinato y la policía puso en libertad al sospechoso que permanecía en la cárcel como causante del asesinato y, un tiempo después, el orangután fue vendido a un zoológico.

Por último, la historia de El misterio de Marie Rogêt es la continuación del cuento que acabamos de nombrado anteriormente, Los crímenes de la calle Morgue. En esta historia, vuelve a aparecer Dupin, y en este caso, tendrá que resolver la desaparición, y posteriormente la muerte de la joven Marie Rogêt. En este cuento, Poe se inspiró en el asesinato de la señorita Mary Cecilia Rogers, en Nueva York.

La historia comienza con la dama Marie Rogêt viviendo en casa de su madre, una viuda que tenía una pensión en la calle Pavée Saint André. Marie salió el domingo por la mañana y le dijo a su pretendiente, Jacques Saint-Eustache, que tenía la intención de pasar el día en casa de una de sus tías que vivía en la rue des Drômes. El lunes se supo que Marie Rogêt no había ido a casa de su tía. Hasta el cuarto día de su desaparición no fue encontrada por unos marineros flotando en el río Sena,. En su cuerpo se apreciaban numerosos signos de violencia física, además de que tenía la ropa destrozada.

No se estaba obteniendo ningún resultado de la investigación y, ante esta situación, se encargó a Dupin que encontrara al culpable del asesinato de la señorita Marie. Días antes, dos muchachos habían descubierto junto a la Barrière du Roule una falda azul y un chal de seda, colocados sobre piedras, que servían de asiento, una sombrilla y un pañuelo, que llevaba el nombre de la víctima. El descubrimiento de estos objetos, unido al estado del lugar, probaba que Marie Rogêt había sido asesinada allí tras haber sostenido una lucha con su agresor.

Dupin, deducción tras deducción, llega a una solución: la joven había sido asesinada por un oficial de marina con el cual ya había huido en una ocasión, cuando trabaja en casa de un perfumista.

Como podemos ver en estos relatos de Poe, la ciudad tiene una gran presencia a lo largo de la obra. Aunque en los cuentos Los crímenes de la calle Morgue y El misterio de Marie Rogêt sí que observamos a lo largo de la historia alguna referencia a la metrópolis -en concreto, la de París «mientras buscábamos entre luces y las sombras de la populosa ciudad esa infinidad de excitantes espirituales que puede proporcionar la observación silenciosa» (Allan Poe, 2001: 232), por ejemplo, en El misterio de Marie Rogêt, 
continuamente vemos presente el lugar donde se ha producido el asesinato, el rio Sena; no hay una alusión tan directa y descriptiva como en El hombre de la ciudad. En este relato, de una extensión de seis páginas, Poe describe perfectamente la ciudad, desde la zona centro hasta los barrios más inseguros de la periferia de Londres y, a su vez, a los transeúntes de esta. Londres se encuentra constantemente presente a lo largo del relato: «Dicha calle es una de las principales de la ciudad, y durante todo el día había transitado la multitud» (Allan Poe, 2001: 132) o "cuando llegamos de nuevo a ese punto donde se concentra la actividad comercial de la populosa ciudad a la calle del hotel D [...]» (Allan Poe, 2001: 138), descrita con una gran minuciosidad, nos da una perfecta visión de cómo era la vida en la urbe en el siglo XIX. Contemplamos las contradicciones y características que marcaron el nacimiento de la ciudad industrial moderna y cómo Poe la relacionará con lo tenebroso, con lo perverso; ya que con su surgimiento sacaba lo peor de la humanidad, de forma que aumentaba el crimen deshumanizado (si vemos en ambos cuentos, todos los crímenes son el las grandes capitales de Londres y París). Esto provocará el mejor ambiente para que Poe desarrolle un género que, a lo largo del tiempo, se convirtió en unos de los más aclamados de la literatura: el género detectivesco. Veremos que una de las características de este, la posibilidad que tiene el homicida de esfumarse entre la gran multitud, estará muy presente también en la obra de Charles Baudelaire.

Una de las grandes aportaciones de Poe es ser de los primeros en caracterizar a la multitud urbana que, como veremos, se convertirá en uno de los temas principales para los artistas del próximo siglo. Poe, en El hombre de la multitud, ve a la muchedumbre como un grupo uniforme, que, si no se observa profundamente, uno no se percata de sus diferentes características. Esta masa se encuentra en movimiento constante, con celeridad. Esta caracterización que le da Poe, Walter Benjamin la equipara con el proceso de producción capitalista: «En sus abruptos movimientos imita igual de bien la maquinaria que da codazos a la materia y la coyuntura que se los da a la mercancía» (Benjamin, 1988: 69). Poe nos revela hasta qué punto la ciudad ha deshumanizando al hombre, pues su apremio, sin prácticamente un segundo para respirar, sin poder perder tiempo alguno para ser lo que hasta en ese momento había sido el ser humano: libre. El hombre había dejado de ser animal, un ser de la naturaleza, para ser una máquina, un ser frío, apático y homogéneo que repetía una rutina constante, eliminando la individualidad, es decir, matando la espontaneidad, de forma que se provoca la muerte del artista.

Otro elemento que Poe introduce, y que elaborará Baudelaire con una mayor profundidad, es el concepto del flanêur, aunque Poe lo enfoca con la imagen del asesino que utiliza a la multitud para 
huir, para ocultar sus fechorías, distinto al que elaborara el poeta francés.

\section{Charles Baudelaire}

Charles Baudelaire nació en 1821 en París y murió en la misma ciudad en 1867. Era hijo del exsacerdote Joseph-François Baudelaire, que falleció en 1827, y de Caroline Dufayis. Después del fallecimiento de su padre, su madre se casó con un militar, a quien Baudelaire nunca aceptó. Cuando cumplió la mayoría de edad, gastó prácticamente toda la herencia paterna que había obtenido. Llevaba una vida de excesos, en 1845 comenzó su idilio con el hachís y se dedicó a la crítica de arte; publicó en Le Salon ese mismo año. En 1856, publica su obra cumbre, Las flores del mal, que marca un antes y un después en el mundo de la poesía. El poemario produjo un gran revuelo y unas fuertes críticas, y fue llevado ante un tribunal por cargos contra la ofensa a la moral pública y las buenas costumbres. Murió en 1867 debido a la sífilis que padecía y que en 1865 le había provocado una parálisis. Baudelaire se convirtió en el mayor exponente del simbolismo y fue considerado uno de los padre de la poesía moderna.

Nos vamos a centrar en un apartado de su obra Las flores del mal, el de Estampas parisienses, en el cual veremos cómo es la París del siglo XIX, podemos estructurarlo en tres partes temáticas: la primera son poemas introductorios, en los que aparecen los elementos que se desarrollarán posteriormente. En el segundo grupo temático se muestra el interés del poeta francés por los suburbios de la metrópolis y le da una visión oscura, influida también por los escritos de Poe. Por último, Baudelaire hace alusión a los sucesos nocturnos, a la vida nocturna de la urbe.

Comenzaremos por uno de los poemas que comienzan en la sección de "Cuadros parisinos», el poema El Sol:

LXXXVII

EL SOL

Por el viejo arrabal, donde cuelgan ruinosas las persianas, abrigo de lujurias premiosas, cuando el sol cruel hiere a golpes redoblados la ciudad y los campos, los techos y los prados, yo salgo a ejercitarme en mi bizarra esgrima, husmeando en los rincones el azar de la rima, tropiezo en las palabras como en el empedrado, y doy contra algún verso largo tiempo soñado.

Este padre nutricio, que odia enfermizas cosas, en los campos despierta los versos y las rosas; 
hace que se evaporen en el cielo las penas, y llena los cerebros de miel y las colmenas. Rejuvenece a los portadores de muletas, dulces y alegres tórnalos como niñas coquetas, y a las mieses ordena madurar y crecer... ¡Al inmortal que siempre quiere reflorecer!

Cuando como un poeta desciende a las ciudades, ennoblece hasta las más viles realidades, y como rey, sin séquito ni músicas marciales, entra así en los palacios como en los hospitales.

Sin duda, en este poema, el poeta francés nos muestra París, como una ciudad endeble, en un movimiento constante, y es el Sol, al amanecer, el que le muestra al poeta la ciudad de París tal y como es en realidad, la que nunca vuelve a ser igual que el día anterior y tampoco lo será al día siguiente. Baudelaire describe los grandes cambios que se están produciendo en París en un periodo de tiempo muy breve debido a la Revolución Industrial.

A continuación, veremos el poema $A$ una transeúnte:

\section{XCIII}

A UNA TRANSÚNTE

La calle aturdidora en torno de mí aullaba.

alta, fina, de luto dolor majestuoso,

una mujer pasó que con gesto fastuoso

recogía las blondas que su andar balanceaba.

Ágil y noble, con sus piernas de escultura.

Por mi parte bebí, como un loco crispado

en su pupila, cielo de huracán preñado,

placer mortal y a un tiempo fascinante dulzura.

¡Un relámpago...y noche! Fugitiva beldad

cuya mirada me ha vuelto de golpe renacer.

¿No he de volver a verte sino en la eternidad?

¡Lejos de aquí! ¡O muy tarde! ¡O jamás ha de ser!

Pues donde voy no sabes, yo ignoro adónde huiste.

¡Tú, a quien yo hubiese amado, tú, que lo comprendiste!

En estos versos, Baudelaire nos relata la aparición de una mujer que surge de la muchedumbre anónima en una calle de la ciudad, lo que le conmociona. Esta conmoción producida por esa aparición inesperada de lo desconocido, aun antes de existir, es una de las experiencias típicas del hombre de la metrópolis. En un mundo tan 
impersonal como el industrial, se le presenta lo nuevo, algo aún por conocer, algo que aún se tiene que revelar, una inquietud sin fin.

En este último poema, podemos deducir que la ciudad moderna, como nos dice Baudelaire, puede provocar dos tipos de experiencia: la desgraciada, producida por el mundo industrial, o, por el contrario, una experiencia positiva. Baudelaire consigue dejar atrás los prejuicios del romanticismo frente a la ciudad, pues ya no hay vuelta atrás hacia la naturaleza, y tiene que adaptarse a lo nuevo, a lo esporádico. Baudelaire tendrá una visión fetiche de la urbe que es capaz de lo mejor y de lo peor.

El poeta «introdujo a este caminante romántico y eterno en la metrópolis, le confió la misión de espiar a la multitud y le exigió esa pasión por los viajes, ese odio hacia todo domicilio estable y ese gusto por el disfraz y la máscara» (López Castellón, 1999: 68).

En esta situación es cuando se comprende la figura del flanêur frente a la de la muchedumbre. El flanêur está inspirado en el cuento El hombre de la ciudad de Poe, en la imagen del anciano que se introduce en la multitud, la del asesino que intenta desaparecer tras su crimen. Baudelaire desarrolla esa idea, pero no de la manera negativa de Poe, sino comprendiendo que el flanêur, el paseante, es el que mejor llega a comprender la gran metrópolis moderna, pues, aunque él llega a mezclarse entre la multitud, nunca es como ella, porque nunca se deja embriagar totalmente; siempre está alerta, y llega así a obtener una experiencia positiva de la urbe. Al mismo tiempo forma parte de algo y, a la vez, está fuera.

Baudelaire no quiere formar parte de la multitud por completo, pues en ella ve la nueva naturaleza, la creada por el mundo industrializado, la que se encuentra sometida a lo que dicte el mercado, y no quiere pertenecer a ella, ya que el flanêur quiere conservar su autonomía.

\section{Federico García Lorca}

Federico García Lorca nació en Fuente Vaqueros, España, en 1898. Fue un poeta y dramaturgo español de gran reconocimiento mundial, famoso por pertenecer a la famosa generación del 27. Pasó su infancia en un pequeño pueblo granadino y acabo sus estudios universitarios en la Universidad de Granada. En 1919, se fue a vivir a la Residencia de Estudiantes de Madrid, donde haría amistad con otros artistas como Salvador Dalí o Luis Buñuel. A lo largo de los años treinta, iría obteniendo un cierto renombre con sus obras, como el poemario Canciones, de 1927, y con Romancero gitano, en 1928. Durante 1929, Lorca fue invitado a pasar una estancia en Nueva York, periodo durante el cual escribiría su obra Poeta en Nueva York, que fue publicada póstumamente. Más tarde escribió obras dramaturgas que no tenían nada que envidiar a su poesía. Durante la guerra civil 
española, fue atrapado por el bando franquista, y asesinado por alteración del orden social.

Para comprender mejor Poeta en Nueva York, obra con una gran connotación surrealista típica del poeta granadino, pero diferente a la de sus obras anteriores, Federico García Lorca definió su obra de este modo: «interpretación personal, abstracción impersonal, sin lugar ni tiempo dentro de aquella ciudad mundo. Un símbolo patético: sufrimiento». Hizo estas declaraciones a La Gaceta Literaria, donde Gil Benumeya lo entrevistó en el año 1931. Veremos que en el poemario se producen dos enfoques: el primero es la visión del poeta respecto a la ciudad neoyorquina, la cual, como veremos, estará influenciada por la angustia que vivía Lorca a causa de su situación personal, debido a que, en esa época, la homosexualidad no estaba bien vista; y el otro enfoque es la imagen de Nueva York como ciudad mundo, ejemplo del imperialismo llevado por el país norteamericano, y que era el ejemplo de la discriminación social, muy lejos de esa visión de la urbe como signo del progreso de los años anteriores.

Esta visión de la ciudad, como símbolo del dolor, le hace simpatizar por su paralelismo personal. Lorca convierte esta obra en una especie de protesta social, por la situación social que se estaba produciendo, por ejemplo en la clase social afroamericana, como podemos observar en el poema Los negros, en el que aparece el conflicto de la discriminación, además del factor pobreza que sufren:

Odian la sombra del pájaro

Sobre el preamar de la blanca mejilla

y el conflicto de luz y viento

en el salón de la nieve fría.

Odian la flecha sin cuerpo, el pañuelo exacto de la despedida, la aguja que mantiene presión y rosa en el gramíneo tabor de la sonrisa.

Aman el azul desierto, las vacilantes expresiones bovinas, la mentirosa luna de los polos, la danza curva del agua en 1a orilla.

Con la ciencia del tronco y del rastro llenan de nervios luminosos la arcilla y patinan lúbricos por agua y arenas gustando la amarga frescura de su milenaria saliva.

Es por el azul crujiente, 
azul sin un gusano ni una huella dormida, donde los huevos de avestruz quedan eternos y deambulan intactas las Iluvias bailarinas.

Es por el azul sin historia, azul de una noche sin temor de día, azul donde el desnudo del viento va quebrando los camellos sonámbulos de las nubes vacías.

Es allí donde sueñan los torsos bajo la gula de la hierba.

Allí los corales empapan la desesperación de la tinta, los durmientes borran sus perfiles bajo la madeja de los caracoles

y queda el hueco de la danza sobre las últimas cenizas.

Podemos ver que aparece el símbolo del pájaro, al que siempre se le había dado el concepto de libertad, pero podemos ver que Lorca lo contrapone como la representación del hombre blanco, oprimiendo al negro. Además, al dar a los afroamericanos una relación más cercana a la naturaleza, se les relaciona con el color azul del edén; sin embargo, esa pureza se encuentra en peligro por la dominación blanca.

En el poema Oficina y denuncia, vemos cómo es la cúspide final de todo el pensamiento de Lorca sobre la metrópolis:

Debajo de las multiplicaciones

hay una gota de sangre de pato.

Debajo de las divisiones

hay una gota de sangre de marinero.

Debajo de las sumas, un río de sangre tierna;

un río que viene cantando

por los dormitorios de los arrabales,

y es plata, cemento o brisa

en el alba mentida de New York

[......]

Hay un mundo de ríos quebrados y distancias inasibles

en la patita de ese gato quebrada por el automóvil,

y yo oigo el canto de la lombriz

en el corazón de muchas niñas.

Óxido, fermento, tierra estremecida.

Tierra tú mismo que nadas por los números de la oficina.

¿Qué voy a hacer, ordenar los paisajes?

¿Ordenar los amores que luego son fotografías,

que luego son pedazos de madera y bocanadas de sangre?

No, no; yo denuncio,

yo denuncio la conjura 
de estas desiertas oficinas

que no radian las agonías,

que borran los programas de la selva,

y me ofrezco a ser comido por las vacas estrujadas cuando sus gritos llenan el valle

donde el Hudson se emborracha con aceite.

Ante esta situación decadente de la urbe, como hemos nombrado anteriormente, unida al paralelismo de la suya, veremos cómo se produce una desrealización del lugar y se evoca la utilización de lugares y características arquitectónicas (ventanas, escaleras, etcétera) para poder así describir la ciudad tal y como es en realidad.

García Lorca hace de Poeta en Nueva York el ejemplo de que la gran metrópolis es el símbolo de la decadencia de la sociedad industrializada la cual ha deshumanizado al ser humano.

\section{Conclusiones}

A lo largo de este trabajo hemos visto las relaciones que ha habido entre artista y ciudad, que, como podemos observar, han sido variadas. Primero desde la visión de Poe, esa imagen de una Londres, más industrializada que las otras ciudades de su época, marcaría lo que iba a ser la sociedad humana a partir de entonces, nuevo mundo para el artista, puesto que sus sensaciones y sus experiencias no iban a ser iguales como las que se habían vivido antes del Romanticismo. Baudelaire ve en esa París en la que él vive una nueva realidad, como predecía Poe; no idílica, pero sí alentadora. No era tranquilizante, los hombres se iban a convertir en simples objetos entre objetos, pero esta realidad abría nuevos caminos para el artista. Por último, toda esa incógnita que tenía la ciudad, que Baudelaire describe como un lugar que saca lo peor del ser humano y como un lugar lleno de experiencias nuevas que ni se había imaginado; Lorca, en su estancia en Nueva York, y con la ciudad industrial plenamente desarrollada, ve como la metrópolis ha creado una sociedad desalmada que es capaz de construir grandes rascacielos y, a la vez, dejar en la calle a mujeres y niños. Pedirá que el ser humano vuelva a la naturaleza y que acabe con lo que le había convertido la urbe, es decir, un ser egoísta y autodestructivo.

Por lo tanto, podemos observar que la ciudad ha tenido diferentes perspectivas y que, al final, esta será positiva o negativa según la interpretación de cada uno. Por ejemplo, podemos encontrar un posicionamiento positivo en el escritor norteamericano Whitman, debido a su identificación total con la masa de Manhattan. Sin embargo, será general la visión de la metrópolis como ente que convierte a las personas en seres banales y el escritor es el único que percibe esta situación y puede tener una visión crítica sobre esto. 
Nuestro mundo ya no iba a ser tan comprensible como lo fue anteriormente, sino que se había convertido en un conglomerado de hechos muy diferentes, en la libre interpretación, en un lugar inestable, que, como diría el sociólogo Zigmunt Bauman, en unos tiempos líquidos, donde los valores sociales de las personas nunca tienen suficiente tiempo para solidificarse -debido a su brevedad-, impide que haya unos marcos de referencia para las acciones humanas. Esta situación dará un sinfín de posibilidades para los escritores.

\section{Bibliografía}

Allan Poe, Edgar. 2001. Cuentos. Madrid: Alianza Editorial.

Baudelaire, Charles. 2011. Las flores del mal. Barcelona: Editorial Planeta.

Benjamin, Walter. 1988. Poesía y capitalismo, Iluminaciones II. Madrid: Taurus.

Cañas, Dionisio. 1994. El poeta y la ciudad. Madrid: Ediciones Cátedra.

De Certeau, Michel. 2008. "Andar en la Ciudad». Revista Bifurcaciones 7 (julio): 1-17.

Fischer, Ernst. 1972. El Artista y su época. Madrid: Fundamentos.

García Lorca, Federico. 2011. Poeta en Nueva York. Madrid: Espasa.

García-Posada, Miguel. 1981. Lorca: interpretación de Poeta en Nueva York. Madrid: Akal.

López Castellón, Enrique. 1999. Simbolismo y bohemia: la Francia de Baudelaire. Madrid: Akal. 